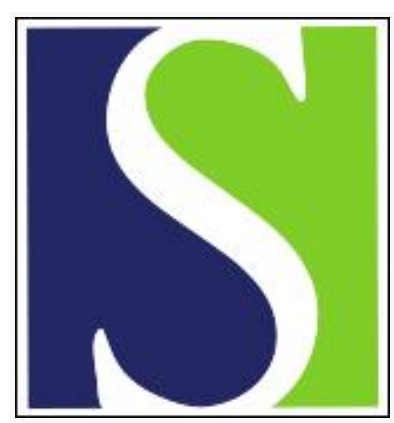

Scand J Work Environ Health 1986;12(4):385-388

https://doi.org/10.5271/sjweh.2124

Issue date: Aug 1986

Effects of different weight loads on the body during motorcycle riding.

by Matsumoto T, Fukaya Y, Yokomori M

This article in PubMed: www.ncbi.nlm.nih.gov/pubmed/3775328

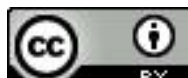




\title{
Effects of different weight loads on the body during motorcycle riding
}

\author{
by Tadao Matsumoto, MD, ${ }^{1}$ Yukio Fukaya, ${ }^{1}$ Motomu Yokomori, $\mathrm{PhD}^{2}$
}

\begin{abstract}
MATSUMOTO T, FUKAYA Y, YOKOMORI M. Effects of different weight loads on the body during motorcycle riding. Scand J Work Environ Health 12 (1986) 385-388. The authors examined the physiological changes of men riding motorcycles carrying different loads. Nine healthy professional riders were the subjects. They used professional Honda MD 90B-90CC motorcycles. Each subject made test rides with the loads of $0,10,15$, and $20 \mathrm{~kg}$, taken at random, on a concrete road for $20 \mathrm{~min}$ at a speed of $30 \mathrm{~km} / \mathrm{h}$. The environmental temperature at the time of the test, skin temperature, vibration sense threshold at a vibration level of $125 \mathrm{~Hz}$, critical flicker fusion frequency, pinching power, grasping power, pulse rates, and blood pressure were measured. The pulse rates were significantly different for the rides with the four different loads, and the changes in pulse rate after the ride with the loads of 10 and $20 \mathrm{~kg}$ were comparatively higher than those before the ride. The changes of systolic blood pressure after the rides with the loads of 15 and $20 \mathrm{~kg}$ were significantly higher than those before the rides. The other changes observed were not significantly different.
\end{abstract}

Key terms: postman, pulse rates, skin temperature, systolic blood pressure, vibration hazard, vibration sense threshold, weight load.

It has been reported that professional speedway riders in the British motorcycle league show a high prevalence of vibration-induced white finger (VWF) (1).

In Japan, for the past 10 years, postal matters have increased so remarkably that motorcycles have begun to be used for speedy and efficient delivery and collection. And both the size and speed of the motorcycles used have increased $(4,6,7)$.

The vibration hazards induced by motorcycle riding have also become widespread in Japan $(4,6)$. It has been recently reported that the maximum acceleration level of vibration on the handlebars of motorcycles used for postal delivery on paved roads exceeds the exposure guidelines of the International Organization for Standardization (10).

Thus preventive measures against such hazards are needed. In the present study we attempt to determine the differences in physiological variables of motorcycle riders in respect to different loads carried on the motorcycle while being ridden on a concrete road.

\section{Subjects and methods}

The tests were made in August. The atmospheric temperature at the time of the test was $27-28^{\circ} \mathrm{C}$. Nine

\footnotetext{
1 Department of Public Health, Nagoya City University Medical School, Kawasumi, Mizuho-cho, Mizuho-ku Nagoya 467, Japan.

2 Transport Machine Engineering, Faculty of Science and Technology, Meijo University, 1-501 Shiogamaguchi, Tempaku-ku, Nagoya 468, Japan.
}

Reprint requests to: Dr T Matsumoto, Department of Public Health, Nagoya City University Medical School, Kawasumi, Mizuho-cho, Mizuho-ku, Nagoya 467, Japan. postmen who were healthy professional riders were examined. Their average age, average years of motorcycle riding, average height, and average weight are shown in table 1 . The subjects were in the usual clothes of a postman, except for gloves, during the experiments.

The type of motorcycle used for the experiments was a Honda MD 90B-90 CC. Before the start of the experiments, the cold inflation pressures of the tires were adjusted to the indicated values. Loads were made of bundles of newsprint paper and fixed to the motorcycle in the following ways: (i) attached in front of the handlebars in a bag above the front wheel and (ii) in a case fixed above the rear wheel. A road paved with concrete was used for the experiments, and there was nothing on the road which interfered with the experiments.

The tests were composed of the four stages shown in table 2. During the tests weights of $0,10,15$, and

Table 1. Characteristics of the subjects.

\begin{tabular}{lrr}
\hline Characteristic & Mean & SD \\
\hline Age (years) & 35.0 & 9.6 \\
Years with motorcycles & 17.5 & 12.1 \\
Height (cm) & 165.0 & 5.7 \\
Weight $(\mathrm{kg})$ & 61.2 & 10.0 \\
\hline
\end{tabular}

Table 2. Weight of the load above the wheels.

\begin{tabular}{lrrrrr}
\hline & \multicolumn{4}{c}{ Stage } \\
\cline { 2 - 5 } & 1 & 2 & 3 & 4 \\
\cline { 2 - 5 } & & 0 & 5 & 10 & 10 \\
Load above the front wheel $(\mathrm{kg})$ & \multicolumn{1}{c}{$\begin{array}{r}\text { 10 } \\
\text { Load above the rear wheel }(\mathrm{kg})\end{array}$} & 0 & 5 & 5 & 10 \\
\hline Total load $(\mathrm{kg})$ & 0 & 10 & 15 & 20 \\
\hline
\end{tabular}




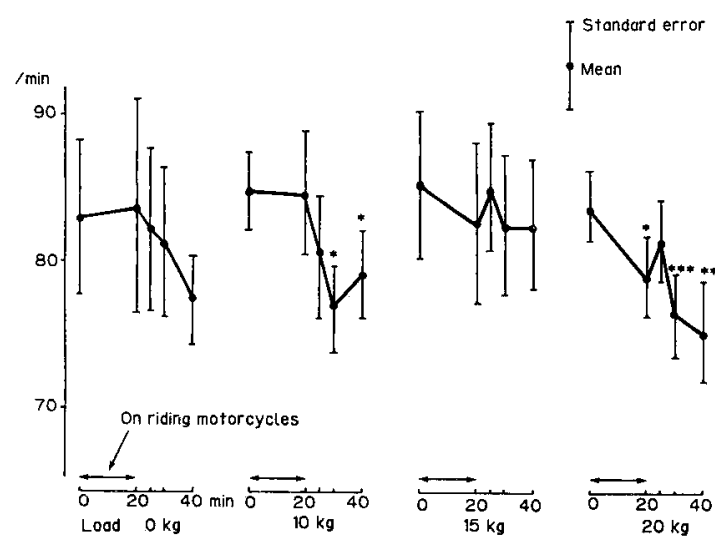

Figure 1. Changes in the pulse rate of the motorcycle riders according to the loads carried on the motorcycle ( ${ }^{*} p<0.05$, $\left.{ }^{* *} \mathrm{p}<0.01,{ }^{* * *} \mathrm{p}<0.001\right)$.

Table 3. Changes in the systolic blood pressure $\left(\mathrm{mm} \mathrm{Hg}^{\mathrm{a}}\right)$ of the subjects. (SE = standard error of the mean)

\begin{tabular}{rlrlll}
\hline \multirow{2}{*}{ Load } & \multicolumn{2}{c}{$\begin{array}{c}2 \\
\text { Before the ride }\end{array}$} & & \multicolumn{2}{c}{$\begin{array}{c}20 \text { min after } \\
\text { the ride }\end{array}$} \\
\cline { 2 - 3 } \cline { 6 - 6 } & Mean & SE & & Mean & SE \\
\hline $0 \mathrm{~kg}$ & 114.8 & 3.2 & & 110.4 & 2.6 \\
$10 \mathrm{~kg}$ & 117.7 & 4.1 & & 115.3 & 3.2 \\
$15 \mathrm{~kg}$ & 116.8 & 2.7 & & $110.7^{*}$ & 3.6 \\
$20 \mathrm{~kg}$ & 116.9 & 3.4 & & $110.0^{*}$ & 3.6 \\
\hline
\end{tabular}

a $1 \mathrm{~mm} \mathrm{Hg} \approx 133.322 \mathrm{~Pa}$.

$* \mathrm{p}<0.05$.

Table 4. Changes in the diastolic blood pressure $\left(\mathrm{mm} \mathrm{Hg}^{\mathrm{a}}\right)$ of the subjects. (SE = standard error of the mean)

\begin{tabular}{|c|c|c|c|c|}
\hline \multirow[t]{2}{*}{ Load } & \multicolumn{2}{|c|}{ Before the ride } & \multicolumn{2}{|c|}{$\begin{array}{l}20 \text { min after } \\
\text { the ride }\end{array}$} \\
\hline & Mean & SE & Mean & SE \\
\hline $\begin{array}{r}0 \mathrm{~kg} \\
10 \mathrm{~kg} \\
15 \mathrm{~kg} \\
20 \mathrm{~kg}\end{array}$ & $\begin{array}{l}72.1 \\
76.0 \\
68.8 \\
72.1\end{array}$ & $\begin{array}{l}2.7 \\
3.1 \\
2.4 \\
2.6\end{array}$ & $\begin{array}{l}67.1 \\
72.4 \\
67.7 \\
69.0\end{array}$ & $\begin{array}{l}1.7 \\
1.7 \\
2.8 \\
2.7\end{array}$ \\
\hline
\end{tabular}

a $1 \mathrm{~mm} \mathrm{Hg} \approx 133.322 \mathrm{~Pa}$.

$20 \mathrm{~kg}$ were randomly carried on the motorcycle of each subject. The peripheral circulatory function was assessed by skin temperature. The skin temperature was measured by a digital thermometer (type D-111, Takara Thermistor Instrument Ltd), of which the thermistor was attached to the back of the middle phalanx of the fourth finger of both hands.

Sensory function was assessed from the vibratory sense threshold. The vibratory sense threshold was measured by a vibration sensation meter (model AU-02, Rion Co) at the frequency of $125 \mathrm{~Hz}$ (7). The measured energy of $0 \mathrm{~dB}$ equaled $298 \mathrm{~mm} / \mathrm{s}$ (peak value). The measured point was on the palmar side of the fingertip of both hands.
The activity of the central nervous system in connection with fatigue was assessed by the critical flicker fusion (CFF) frequency, which was measured by a flicker meter (type FL-10, Sibata Kagaku Co, Ltd). The median value of the three measured CFF frequencies at each time was then assessed (2).

Motor function was evaluated by the pinching and grasping power of the rider. Pinching power was measured by a pinch power meter (MPS-5, Tokyo Iryoki Co, Ltd) between the thumb and the index finger of the right hand (5). The grasping power of the right hand was measured by a dynamometer-YO (Smedley).

The systemic circulation of the blood was assessed by the systolic and diastolic blood pressures, measured by a Riva-Rocci sphygmomanometer and by pulse rates. The pulse was counted for $15 \mathrm{~s}$ at a place where it could be felt and was then quadrupled to get the rate per minute.

The environmental temperature in which the test took place was also recorded when each measurement was taken. After the subjects had been at the starting point before riding for more than $30 \mathrm{~min}$, the foregoing measurements were taken. Then they rode the motorcycles for $20 \mathrm{~min}$ with the indicated load and at the speed of $30 \mathrm{~km} / \mathrm{h}$. Each variable was measured immediately after the end of the ride and at 5,10, and $20 \mathrm{~min}$ after the ride.

In the statistical analyses Student's t-test for paired data was used for testing the differences between the values before and after the riding of the motorcycles. The computer FACOM M-200 with the program Statistical Package for the Social Sciences was used at the Nagoya University Computation Center for the statistical analyses.

\section{Results}

The degree of decrease in the skin temperature on the finger of the right hand was remarkable after the ride with loads from 0 to $20 \mathrm{~kg}$. The skin temperature on the right hand after the ride with the load of $20 \mathrm{~kg}$ was slow to recover; the mean value of the temperature did not reach the value before the test until $20 \mathrm{~min}$ after the end of the ride. A similar tendency was seen for the left hand, but the decrease in the skin temperature of the right hand immediately after the ride was much larger than that of the left hand.

The degree of increase in the vibration sense threshold of both hands was remarkable after the ride with the loads of 0 to $20 \mathrm{~kg}$. It also decreased slowly. The increase in the vibration sense threshold of the right hand was larger than that of the left hand; moreover the threshold of the right hand was later to recover than that of the left hand. The recovery of the right hand at $20 \mathrm{~min}$ after the end of the ride was not yet equal to the pretest value.

The CFF frequency was considerably increased at 5 and 10 min after the end of the ride with the load 
Table 5. Summary of the results. $(D=$ decrease, $I=$ increase, $N C=$ no change).

\begin{tabular}{|c|c|c|c|c|c|c|c|c|}
\hline \multirow{3}{*}{ Variable } & \multicolumn{8}{|c|}{ Load $^{a}$} \\
\hline & \multicolumn{2}{|c|}{$0 \mathrm{~kg}$} & \multicolumn{2}{|c|}{$10 \mathrm{~kg}$} & \multicolumn{2}{|c|}{$15 \mathrm{~kg}$} & \multicolumn{2}{|c|}{$20 \mathrm{~kg}$} \\
\hline & A & $\mathrm{B}$ & A & B & A & B & A & B \\
\hline \multicolumn{9}{|l|}{ Skin temperature } \\
\hline Right hand & $D^{* *}$ & $\mathrm{NC}$ & $D^{* \star \star}$ & $1^{*}$ & $D^{* * *}$ & $I^{* *}$ & $D^{* \star \star}$ & $D^{* *}$ \\
\hline $\begin{array}{l}\text { Left hand } \\
\text { Vitration sense threshold }\end{array}$ & $D^{* *}$ & NC & $D^{* *}$ & NC & $D^{* *}$ & $I^{* *}$ & $D^{* *}$ & NC \\
\hline \multicolumn{9}{|l|}{ Vibration sense threshold } \\
\hline Right hand & $1^{* * * *}$ & $D^{*}$ & $I^{* *}$ & NC & $I^{\star \star \star \star *}$ & $D^{* *}$ & $1^{* * *}$ & NC \\
\hline Left hand & $i^{* *}$ & $\mathrm{NC}$ & $i^{\star *}$ & $\mathrm{NC}$ & $1^{*}$ & NC & $1 * *$ & NC \\
\hline Critical flicker fusion & NC & $1^{*}$ & NC & $D^{*}$ & NC & NC & NC & NC \\
\hline Pinching power & NC & $i^{* \star}$ & NC & $\mathrm{NC}$ & NC & NC & NC & NC \\
\hline Grasping power & NC & NC & NC & $I^{\star \star \star}$ & NC & NC & $D^{*}$ & $I^{*}$ \\
\hline Pulse rate & NC & NC & NC & $D^{* *}$ & NC & NC & $D^{* *}$ & $D^{\star \star \star *}$ \\
\hline Systolic blood pressure & .. & NC & .. & NC & .. & $\mathrm{D}^{* *}$ & .. & $D^{* \star}$ \\
\hline Diastolic blood pressure & $\ddot{. .}$ & $\mathrm{NC}$ & .. & NC & .. & NC &.. & NC \\
\hline
\end{tabular}

a $A=$ comparison between the values before and immediately after the ride, $B=$ comparison between the values before and 5,10 , or 20 min after the ride.

${ }^{\star} p<0.10,{ }^{\star *} p<0.05,{ }^{\star \star *} p<0.01,{ }^{* \star \star *} p<0.001$.

of $0 \mathrm{~kg}$, and it was considerably decreased at $10 \mathrm{~min}$ after the end of the test with $10 \mathrm{~kg}$.

Pinching power was significantly increased at $5 \mathrm{~min}$ after the end of the test with the load of $0 \mathrm{~kg}$.

Grasping power was significantly increased at $5 \mathrm{~min}$ after the end of the ride with the load of $10 \mathrm{~kg}$.

The results of the pulse rates are shown in figure 1. The changes after the ride had a tendency to decrease as the load of the four stages increased. The pulse rates were significantly decreased at 10 and $20 \mathrm{~min}$ after the test with the load of $10 \mathrm{~kg}$ and also immediately, 10 , and $20 \mathrm{~min}$ after the end of the ride with the load of $20 \mathrm{~kg}$.

The results of the blood pressure measurements are shown in tables 3 and 4 . The value of the systolic blood pressure was significantly decreased 20 min after the tests with the loads of 15 and $20 \mathrm{~kg}$. The changes in diastolic blood pressure were not significantly great with any of the four stages.

The results of the paired t-test of the values before and after the tests are summarized in table 5 .

\section{Discussion}

Yamada reported on the changes caused in the skin temperature of the finger by motorcycle riding for 20 $\min$ at $30 \mathrm{~km} / \mathrm{h}$ and by standing outdoors for $20 \mathrm{~min}$ (9). He observed that during the motorcycle riding the finger skin temperature dropped rapidly and that after the end of the ride it recovered gradually. Hisashige made a study on the effects of motorcycle riding (4). He observed that the changes in skin temperature and vibration sense threshold were so considerable that the ride had an effect on the disorders of peripheral circulatory and nervous functions of the hands. He concluded that environmental conditions, especially coldness, had a great impact on the development of vibration disease. Even in our experiments, which were conducted in a warm atmosphere, the changes in skin temperature and vibration sense threshold were great for the tests with the four different loads, but there were no clear differences between any of the loads. These findings suggest that there is a causal relationship between motorcycle riding and the development of vibration disease that is not connected to the load on the motorcycle. The changes in these two variables in the right hand were greater than those in the left hand. Therefore it is surmised that the burden on the right hand was heavier than on the left because of the structure of the motorcycle and the mode of operation.

It is well known that CFF is decreased in connection with fatigue of the central nervous system (2). We observed that the CFF was significantly increased by the load of $0 \mathrm{~kg}$ and decreased by the load of $10 \mathrm{~kg}$, but that the CFF changes were not significant at the loads of 15 or $20 \mathrm{~kg}$. There is no clear explanation for this occurrence as yet, and further investigations should be made on this subject.

The data on the prevalence of extensive muscle fatigue in the hands and arms of machine operators indicate that occupational vibration may be the reason for inadequate muscle contraction (8). Färkkilä et al have demonstrated that acute exposure to vibration leads to a significant decrease in the muscle force of the hands (3). We did not observe any decrease in the pinching power or grasping power after the end of the motorcycle ride. On the contrary, an increase was observed after the ride with the loads of 0 and $10 \mathrm{~kg}$ for the pinching and grasping power, respectively. These data suggest that motorcycle riding with a light load would strengthen muscle activity.

We detected significant changes in the pulse rate and systolic blood pressure with the four loads carried, and it is possible that the heavier the load the greater the change. Apparently these associations have not been reported elsewhere. The effects upon the blood circulatory system during motorcycle riding with different loads would be different. However, it is not clear whether or not heavy loads would be associated 
with the development of the hand-arm vibration syndrome.

Before future standards are set for the weight of mail carried on a motorcycle, the mechanical properties of the hand-arm system which involve the acceleration level of vibration on the handlebars should be taken into consideration.

\section{References}

1. Bentley S, O'Connor DE, Lord P, Edmonds P. Vibration white finger in motorcycle speedway riders. In: Brammer AJ, Taylor W, ed. Vibration effects on the hand and arm in industry. John Wiley \& Sons, New York, NY 1982, pp 189-192.

2. Chandler PJ. Flicker discrimination in relation to nature and severity of CNS dysfunction. Acta Neurol Scand 42 (1966) 558-566.

3. Färkkilä M, Pyykkö I, Korhonen O, Stark J. Hand grip forces during chain saw operation and vibration white finger in lumberjacks. Br J Ind Med 36 (1979) 336-341.
4. Hisashige A. Studies on the vibration disease resulting from driving motorcycle - Relation between working conditions and occupational health hazards among mailmen. J Sci Labour 57 (1981) 349-362.

5 . Kimotsuki K. Measurement of the pinch strength of fingers. J Sci Labour 49 (1973) 663-666.

6. Matsumoto T, Yokomori M, Harada N. Mailmen's vibration hazards induced by motorcycle riding. Jpn $\mathrm{J}$ Ind Health 23 (1981) 485-495.

7. Matsumoto T, Yokomori M, Harada N, Fukuchi $Y$, Kanamori M, Gotoh M. Mailmen's vibration hazards induced by motorcycle riding - Results of cooling load tests. Ind Health 20 (1982) 167-175.

8. Pyykkö I. The hand-arm vibration definitions and assessment of symptoms. In: Gemne G, Taylor W, ed. Handarm vibration and the central autonomic nervous system. Multi-science Publishing, London 1983, pp 6-10.

9. Yamada S. Primary factors for the occurence of white waxy changes of the finger in vibration hazards with presentation of the nail press test. Jpn J Ind Health 14 (1972) 529-541.

10. Yokomori M, Yamada S, Nakagawa T, Matsumoto T. The vibration of the handlebars of a motorcycle in running on the paved road. Jpn J Ind Health 23 (1981) $134-140$. 